\title{
Rarefaction of Body Hair: Differential Diagnoses
}

\author{
Paulo Henrique Martins ${ }^{a} \quad$ Clarissa Mitri Espanhol ${ }^{\mathrm{a}} \quad$ Mariana do Amaral Ferreira $^{a}$ \\ Leandro Damiani ${ }^{b}$ \\ ${ }^{a}$ Department of Dermatology, Santa Casa de Misericórdia de Porto Alegre, Porto Alegre, Brazil; ${ }^{b}$ Division of \\ Dermatology, Dermatology Service, Hair and Scalp Diseases Outpatient Clinic, Santa Casa de Misericórdia, \\ Porto Alegre, Brazil
}

\section{Question}

A 35-year-old male patient who had not received previous treatment sought medical advice because of hair loss for more than 1 year. Upon examination, he had capillary rarefaction in the parietal and vertex region, a characteristic of androgenetic alopecia that was confirmed by digital dermatoscopy.
In the skin review, there were areas of hair rarefaction on the upper and lower limbs (Fig. 1) with erythema and peripapillary desquamation, and some pili torti in the periphery of the plaque were seen by dermatoscopy (Fig. 2, 3). In these areas, the sensitivity was preserved. There was no involvement of the eyebrows, axillary, and pubic hair. The patient denied itching. He had normal thyroid function, and serology for syphilis and antinu-
Fig. 1. Alopecia plaques on the lower limbs (macroscopy).

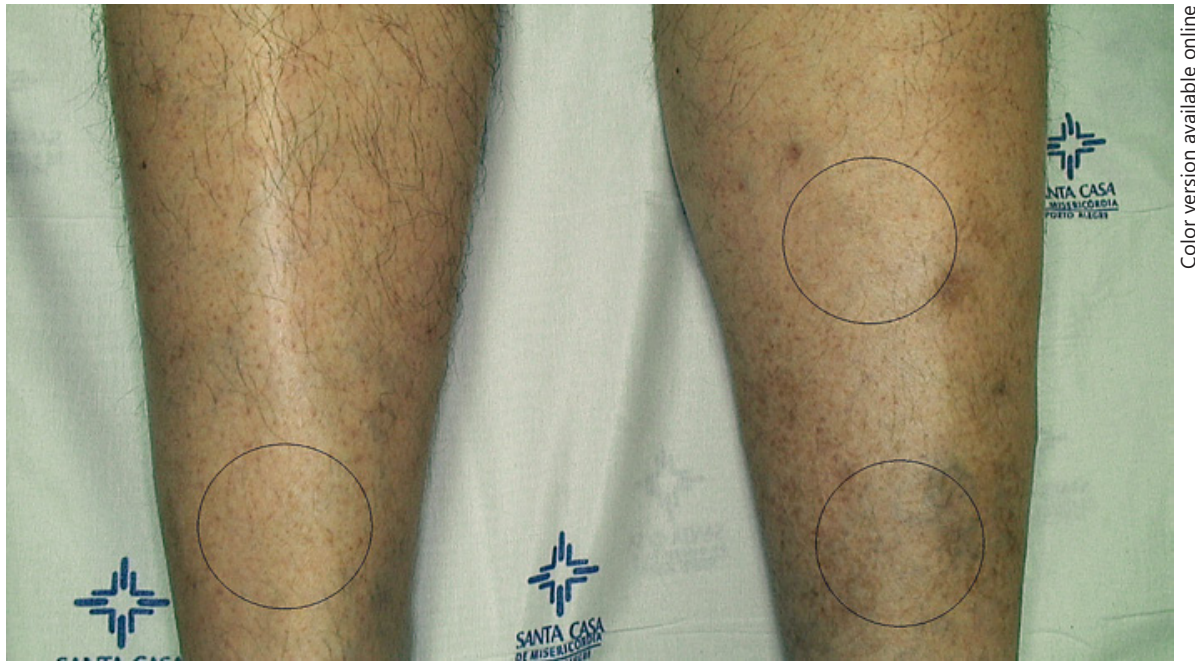

\section{KARGER}

(C) 2019 S. Karger AG, Basel

E-Mail karger@karger.com

www.karger.com/sad
Prof. Paulo Henrique Martins Department of Dermatology Av. Osvaldo Aranha, No. 340, Bom Fim District Porto Alegre, RS 90035190 (Brazil)

E-Mail phenriquemartins0@ gmail.com 


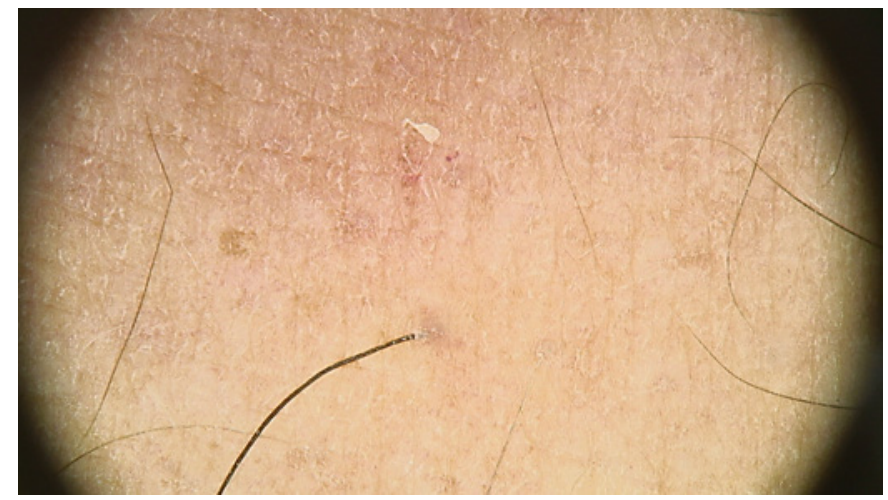

Fig. 2. Erythema and perifollicular scaling (FotoFinder, $\times 70)$.

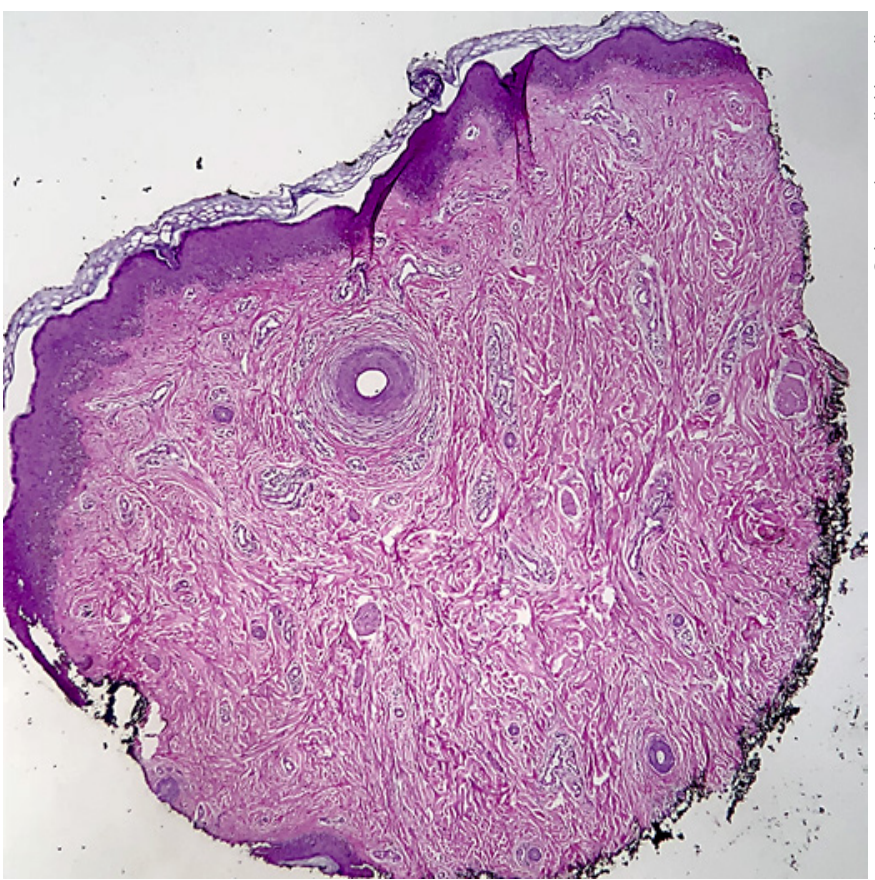

Fig. 4. Perifollicular fibrosis and deep dermal fibrosis in the follicular units (histopathology findings, $\times 100$ ). H\&E.

clear antibodies was negative. The skin of the forearm was biopsied, guided by dermatoscopy. The anatomopathological examination revealed perifollicular fibrosis with discrete circumjacent lichenoid infiltrate and deep dermal fibrosis in the follicular units (Fig. 4, 5). After clinical, dermatoscopic, and anatomopathological cor-

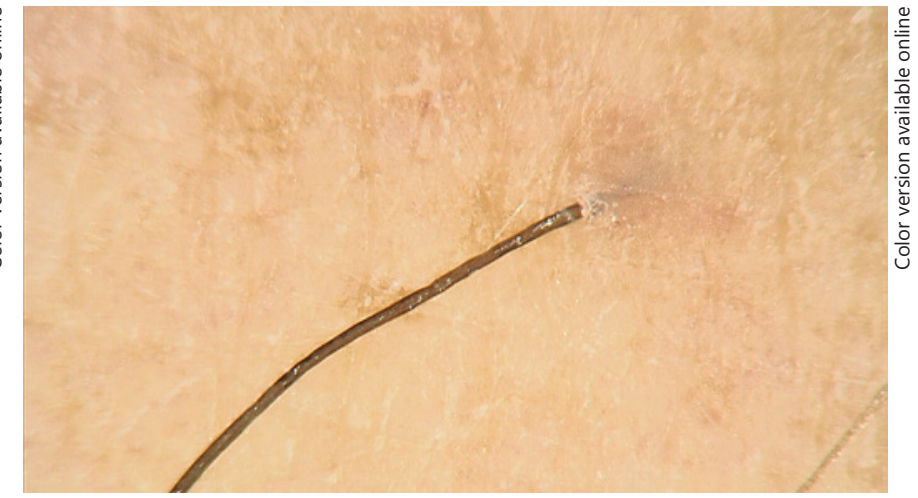

Fig. 3. Erythema and perifollicular scaling (FotoFinder, $\times 100)$.

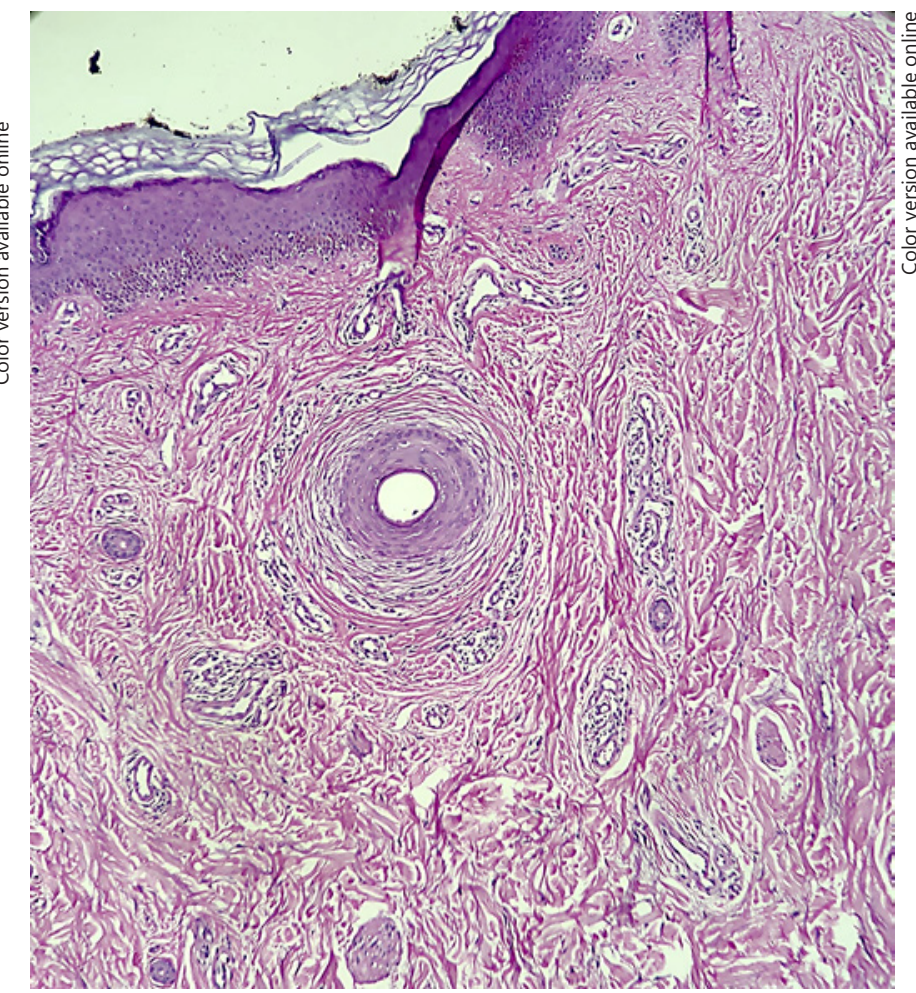

Fig. 5. Perifollicular fibrosis with discrete circumjacent lichenoid infiltrate and deep dermal fibrosis in the follicular units (histopathology findings, $\times 400)$. H\&E.

relation, the diagnosis of corporal cutaneous lichen planopilaris (LPP) was confirmed. The patient decided against treatment and maintained ambulatory followup to observe the evolution and appearance of symptoms on the scalp.

What is your diagnosis?

Skin Appendage Disord 2019;5:414-416 


\section{Answer}

LPP is a common form of primary scarring alopecia [1]. The striking scalp morphology in LPP leading to follicular destruction and scarring has been extensively studied. Reports of body hair involvement in LPP are scant; however, those found predict a generalized disease process. Extra-scalp LPP has mainly been reported in association with its rare variants, which are frontal fibrosing alopecia and Graham Little Piccardi Lassueur Syndrome. Dermatoscopic features of body hair LPP have been rarely studied [2], and there are just some few reports that describe the histopathological features of these lesions.

Classic LPP can occur anywhere on the scalp, typically presenting as scarring alopecia with inflammatory signs such as perifollicular erythema and scaling [3]. Pain, pruritus, or a burning sensation may be associated with and indicate disease activity [4]. The involvement of body hair has been described in classic LPP. However, a clear description of its nature, clinical presentation, and incidence appear to be lacking. In addition, there are few cases similar to the one reported, where plaques of scarring alopecia on the limbs present as the only manifestation of LPP.
Differential diagnoses considered in patients with body hair loss include, among many others, alopecia areata, hypothyroidism, mycosis fungoides, syphilis, and leprosy [5].

However, in the case described, the epidemiological history, clinical presentation, and dermatoscopic findings pointed to the diagnosis of LPP, which was confirmed by histopathology.

\section{Statement of Ethics}

The patient gave his consent to publish his case and the corresponding images.

\section{Disclosure Statement}

The authors declare no conflicts of interest.

\section{Keywords}

Lichen plano pilaris $\cdot$ Hair disease $\cdot$ Cicatricial alopecia

\section{References}

1 Soares, VC, Mulinari-brenner, F, Souza, TE. [Lichen planopilaris epidemiology: a retrospective study of 80 cases]. An Bras Dermatol. 2015;90(5):666-70.

2 Arshdeep BM, Batrani M, Kubba A, Kubba R. Lichen planopilaris beyond scalp: a case series with dermoscopy-histopathology correlation. Int J Dermatol.2018 Nov;57(11):e12731.

3 Asz-Sigall D, González-de-Cossio-Hernández AC, Rodríguez-Lobato E, Ortega-Springall MF, Vega-Memije ME, Arenas Guzmán R.
Linear Lichen Planopilaris of the Face: Case Report and Review. Skin Appendage Disord. 2016 Sep;2(1-2):72-5.

4 Kerkemeyer KL, Green J. Lichen planopilaris: A retrospective study of 32 cases in an Australian tertiary referral hair clinic. Australas J Dermatol. 2018 Nov;59(4):297-301.

5 Vendramini DL, Silveira BR, Duque-Estrada B, Boff AL, Sodré CT, Pirmez R. Isolated Body Hair Loss: An Unusual Presentation of Lichen Planopilaris. Skin Appendage Disord. 2017 Jan;2(3-4):97-9.
Martins/Mitri Espanhol/ do Amaral Ferreira/Damiani 